STUDI

FRANCESI

\section{Studi Francesi}

Rivista quadrimestrale fondata da Franco Simone

165 (LV | III) | 2011

LA RAPPRESENTAZIONE DELLA MADRE NELLA

LETTERATURA FRANCESE DEL NOVECENTO a cura di Dario Cecchetti e Michele Mastroianni

\title{
Bernard Teyssèdre, Arthur Rimbaud et le foutoir zutique
}

\section{Mario Richter}

\section{OpenEdition}

Journals

Edizione digitale

URL: http://journals.openedition.org/studifrancesi/5092

DOI: 10.4000/studifrancesi.5092

ISSN: 2421-5856

Editore

Rosenberg \& Sellier

Edizione cartacea

Data di pubblicazione: 1 décembre 2011

Paginazione: 665-666

ISSN: 0039-2944

Notizia bibliografica digitale

Mario Richter, «Bernard Teyssèdre, Arthur Rimbaud et le foutoir zutique», Studi Francesi [Online], 165 (LV I III) | 2011, online dal 30 novembre 2015, consultato il 12 janvier 2021. URL: http://

journals.openedition.org/studifrancesi/5092 ; DOI: https://doi.org/10.4000/studifrancesi.5092

Questo documento è stato generato automaticamente il 12 janvier 2021.

\section{cc)}

Studi Francesi è distribuita con Licenza Creative Commons Attribuzione - Non commerciale - Non opere derivate 4.0 Internazionale. 


\title{
Bernard Teyssèdre, Arthur Rimbaud et le foutoir zutique
}

\author{
Mario Richter
}

\section{NOTIZIA}

BERNARD TEYSSÈDRE, Arthur Rimbaud et le foutoir zutique, Clamecy, Éditions Léo Scheer, 2011, pp. 776.

1 Quando, negli ultimi giorni di settembre del 1871, Rimbaud si recò a Parigi col fermo intento di mettere in atto il famoso programma del dérèglement da lui esposto nel maggio 1871 nelle due lettere dette "del veggente", cominciò a intraprendere la sua nuova attività poetica nell'ambito di un club ivi frequentato da Verlaine, quello dei "Vilains Bonshommes", al cui interno si era venuto formando un gruppo più spinto $\mathrm{e}$ dissacratore che si era dato il nome di Cercle zutique, dotandosi anche di un Album fregiato dello stesso promettente epiteto. Si tratta di un momento di particolare importanza, anche se la critica ufficiale ha a lungo preferito, considerati gli argomenti scabrosi, parlarne soltanto di sfuggita, quasi con vergogna. Rimbaud collaborò all'Album con assiduità fra il 15 o 16 ottobre e il 17 o 18 novembre 1871: poco più di un mese. Dopo l'edizione integrale che meritoriamente ne fece Pascal Pia nel 1962 (ripubblicata nel 2008), il documento letterario cominciò a suscitare un crescente interesse, soprattutto presso gli specialisti di Rimbaud. Tuttavia, mentre esistono accurati studi d'insieme delle Poésies, dei Vers nouveaux, di Une saison en enfer e delle Illuminations, nulla di analogo, al di là delle preziose ricerche di Steve Murphy, di Michael Pakenham e di qualche altro valente studioso, era finora possibile registrare per l'Album zutique.

Il libro di Bernard Teyssèdre costituisce adesso una benvenuta e persino sovrabbondante risposta a questa carenza critica. L'A. si è impegnato a studiare ogni testo in rapporto al suo contesto immediato e ha seguito con attenzione la carriera di ciascuno degli "zutistes". Non c'è testimonianza che non sia stata da lui ascoltata. È così possibile seguire passo passo, di giorno in giorno e quasi di ora in ora, per un percorso 
che occupa più di 600 pagine, l'attività di Rimbaud in un così breve ma intenso momento della sua vita, e nello stesso tempo conoscere quanto nel mondo letterario e politico parigino per diverse ragioni si legava in quei giorni a tale attività. I testi risultano letti con la più meticolosa attenzione e sono chiariti alla luce del loro particolare lessico, sui cui significati nulla è mai dato per scontato. Desta tuttavia stupore il fatto che l'A., in un libro tanto circostanziato, non si sia interrogato, a proposito del Sonnet $d u$ trou $d u c u l$, sulla ragione per cui Rimbaud in quel testo (che è il primo dell'Album) abbia ortografato il termine "Rêve" (Mon Rêve s'aboucha souvent à sa ventouse) con l'iniziale maiuscola e per quale motivo Verlaine, quando allestirà la raccolta sodomitica Hombres, si prenderà la malsana libertà di intervenire nelle terzine del povero amico (non più in grado di protestare) riscrivendo proprio il verso che contiene la parola "Rêve" nel seguente modo: Ma bouche s'accoupla souvent à sa ventouse. Una riflessione su questo dato oggettivo gli avrebbe senz'altro consentito di chiarire un argomento critico di non secondario interesse, ossia di accertare la diversa natura che l'abbrutimento aveva per i due poeti (per questo problema si vedano le pp. 1093-1094 delle Opere complete di Rimbaud, Biblioteca della Pléiade, Einaudi-Gallimard, 1992). Per accedere ai diversi significati delle singole parole, l'A. si è opportunamente avvalso, oltre che dei dizionari di Bescherelle, Littré, Larchey e Larousse, del Dictionnaire érotique moderne di Alfred Delvau (1864). "Exercice de lecture attentive", come dice l'A., questo libro, arricchito di numerose e istruttive illustrazioni originali, si raccomanda per l'abbondanza e per la precisione delle informazioni, nonché per i numerosi chiarimenti esegetici. 